\title{
Are insect flower visitor assemblages distinguishable between Brassica napus and B. rapa?
}

\author{
Brad G. Howlett*, Ruth C. Butler, Melanie K. Walker and David A.J. Teulon \\ The New Zealand Institute for Plant \& Food Research Limited (PFR), Private Bag 4704, \\ Christchurch Mail Centre, Christchurch 8140, New Zealand \\ ${ }^{*}$ Corresponding author: brad.howlett@plantandfood.co.nz
}

\begin{abstract}
Brassica napus and Brassica rapa are grown across six continents for purposes including oilseed, biofuel, vegetables and livestock fodder. Hybridisation between the two can downgrade seed quality reducing grower returns. We assess the similarity of flower visitor assemblages of both species to determine the applicability of pollinator management strategies to both. Insect taxa were collected using window traps placed within ten peakflowering fields, five each of B. napus and B. rapa (one cultivar/species) located in South Canterbury, New Zealand. Both crops contained similar flower visitor assemblages with 25 of 29 taxa in common. Of the 1549 insects counted, Apis mellifera was most abundant ( 40\% of individuals in both crops). Bombus terrestris and the flies Delia platura, and Oxysarcodexia varia were also common. Crop location more likely influenced assemblage composition than crop species. Strategies to boost the role of bee and non-bee pollinators have potential benefits for both crops; however, a broader understanding of pollinator movement between crops is required to optimise seed purity and crop spacing.
\end{abstract}

Keywords: honey bees, pollination, pollen movement, pollinator management, New Zealand, bumblebees, non-bee, gene flow, solitary bees, pollinator diversity.

\section{INTRODUCTION}

Many commercially important crops, including some Brassica spp., can benefit from pollination by insects. Brassica napus L. (rape) and Brassica rapa L. (turnip) are commonly grown in New Zealand for vegetable and forage seed, oilseed, livestock forage and vegetables but they readily hybridise (Stewart 2002 and references within). A more holistic approach to improving pollinationmanagement strategies is desirable (Rader et al. 2012) so there is a need to understand the composition and effectiveness of managed and wild insect species represented within crop pollinator assemblages. Such information could improve both crop yields (Garratt et al. 2014) and seed purity by minimising inter-crop pollen flow (Mesa et al. 2013). Whether such approaches require focus at the crop-species level will depend partly on the similarity of the pollinators that visit these crops. However, in New Zealand studies assessing the distinctiveness of flowervisitor assemblages between crops are lacking, even for those closely related species such as Brassica napus and Brassica rapa.

Both B. rapa and B. napus can be pollinated by a range of bee and non-bee insect (Rader et al. 2009; Garratt et al. 2014) and in a UK study there is some overlap between insects visiting the flowers of both plants (Ronca et al. 2017). In terms of limiting unwanted gene flow between these crops via insect movement of pollen, studies have often considered the movement of relatively few pollinators, with a particular focus on social bees (e.g. Hayter \& Cresswell 2006). However, more recent studies demonstrate the need to extend consideration to other pollinators, including 
other solitary bee and fly species, as they may also contribute significantly to pollen flow from Brassica crops (Chifflet et al. 2011; Ronca et al. 2017).

In New Zealand, many crop species share a number of verified or potential pollinating species demonstrating their possible flexibility in multi-crop systems. At least four bee species and six fly species are pollinators of $B$. rapa (Rader et al. 2009; Howlett et al. 2011) and some of these have also been shown to pollinate a range of other crops including onion Allium cepa L. (Howlett et al. 2017a); kiwifruit Actinidia.deliciosa (A.Chev.) C.F.Liang \& A.R.Ferguson (Stavert et al. 2016) and avocado Persea americana Mill. (Rader et al. 2016). Moreover, studies list a much broader range of generalist flower visiting species to $B$. rapa crops (Howlett et al. 2009a) many of which also visit onion (Howlett et al. 2005) and carrot Daucus carota subsp. sativus (Hoffm.) Schübl. \& G. Martens (Howlett et al. 2015), kiwifruit (Howlett et al. 2017b) and avocado (Read et al. 2017). Moreover, at least some of these bee and non-bee pollinators have been shown to consistently move between a flowering crop and the surrounding environment (Mesa et al. 2013) and carry viable pollen over distance of at least $400 \mathrm{~m}$ (Rader et al. 2011). Therefore, information about the functional similarity of pollinator assemblages between closely related crops, such as B. rapa and B. napus, is necessary for better utilisation and control of pollinator assemblages within these crops.

Here the key flower-visiting species found in B. rapa and B. napus crops in South Canterbury, New Zealand were examined to determine whether both crops have similar or distinctive flower visitor assemblages. This knowledge is needed to assess whether or not pollinator management strategies might focus on the same mix of managed and wild pollinators for both crops and whether the same set of pollinators may contribute to unwanted pollen flow between the crops.

\section{METHODS}

Fields and sampling for flower-visiting insects

The work was conducted at peak flowering in ten fields comprising five each of $B$. napus 'Winfred' and B. rapa 'Hunter'. These fields were located within a $40-\mathrm{km}$ radius from Hinds, South Canterbury, New Zealand. (44.0023 ${ }^{\circ} \mathrm{S}, 171.5700^{\circ}$ E). The field locations were: Temuka Guild Rd, Hinds, Christys Rd, Mayfield and Waipapa Rd for B. napus; and Temuka Guild Rd, Ward Rd, Dixons Rd, Lismore and Denshires Rd for $B$. rapa. Field size was 5-10 ha and were separated by distances greater than $2 \mathrm{~km}$. Window-trap design and within-field placement were the same as those described in detail in Howlett et al. (2009a). In summary, each trap consisted of a plastic grey tray (area $34.7 \times 21.8 \mathrm{~cm}$, depth $6.0 \mathrm{~cm}$ ) containing water and detergent to capture flying insects. The tray supported two crosswise transparent Perspex ${ }^{\oplus}$ panes that projected $30 \mathrm{~cm}$ above the tray rim. Each trap was supported at crop flower height by a grey plastic holder attached to stakes. Five traps were placed in each field, one in each of four corners, (five metres inside the field boundary) and one trap in the field centre. They were left to capture insects over a period of six days (1-6 November, 2004) during the period at which the crops were at peak flower). Insects were classified into the families Apideae (bees); Diptera (flies); Coleoptera (beetles); and Lepidoptera (butterflies and moths). We only considered insects as flower visitors if they had previously been identified as such within other New Zealand crops including Daucus carota (Howlett et al. 2015), Actinidia deliciosa (Howlett et al 2017b), Persea americana, Allium cepa, Brassica rapa (Howlett et al. 2009a). These were then counted from each trap sample. Insects $<3$ mm diameter were not counted as other studies have considered larger bees and non-bee insects as the key pollinators of both crops (Garratt et al. 2014; Ronca et al. 2017). Moreover, in New Zealand, insects $<3$-mm diameter were not found to play a significant role as pollinators of $B$. rapa (Walker et al. 2009), despite their occurrence within these crops (Howlett et al. 2009b). 


\section{Comparative size of floral structures}

To determine whether the flowers of the chosen Brassica rapa and $B$. napus cultivars could be distinguished based on size, we measured the length of flower pedicels, petals, sepals, stigmas, inner stamens and outer stamens of fully open flowers. A total of 25 flowers were collected per field across all ten fields by selecting a flower from a primary inflorescence of each plant. Five plants were randomly selected within $1 \mathrm{~m}$ of each trap placement.

\section{Statistical analyses}

Total counts of flower-visiting insects were converted into a mean count per species per trap and four sets of analyses were then conducted as follows:

1. Simple Summaries: The total counts per location and among locations using the mean counts per trap at each location.

2. Richness and Diversity: Richness was determined by number of species calculated for each location and across locations for each crop species. Diversity was assessed using Simpson's 1/D (Magurran 2007), where:

$$
D=\sum_{i}\left\{n_{i} \times\left(n_{i}-1\right)\right\} /(N \times(N-1))
$$

and $N$ is the total number of individuals, and $n_{i}$ is the number of individuals for species $i$.

Simpson's 1/D was analysed formally with analysis of variance, and Richness with a Poisson generalised linear model (GLM, McCullagh \& Nelder 1989) with a log. link.

3. Univariate analyses: Numbers of each species at each location were analysed in two ways. The number per location of each species was analysed with a Poisson GLM with a log link, which included an offset (McCullagh \& Nelder 1989) of log(number of traps per site) to adjust the results to counts per trap. Means and associated confidence limits were obtained on the link (log scale) and backtransformed for presentation.
4. Multivariate analyses: A correspondence analysis was used to assess the relationships between flower visiting taxa, fields and crop species. The analysis used data from a twodimensional table of counts, these being field sites and flower visiting taxa. This process allowed identification of those sites and taxa that varied most in the profile from the average over rows or columns. The method and its use have been described in detail by Greenacre (2007). The primary results are presented as an Asymmetric Biplot, illustrating how each location related to the percentage of totals per trap for each species.

Additional analyses were also conducted including a log linear model to determine whether percentages of each flower-visitor taxon varied between crop species, principle components analysis and canonical variates analysis to compare relationships between fields, crop species and flower visiting taxa. These are presented as supplementary material (Additional File 1 https://doi.org/10.30843/ nzpp.2018.71.162.90). All analyses were carried out with Genstat software (Payne et al. 2017).

\section{RESULTS}

\section{Data collected}

Of the 50 traps that were placed across fields (five per field) 47 successfully captured flower-visiting insect samples across the five consecutive days. In seven of the ten fields, all five traps successfully collected samples. Of the remaining fields, four traps provided samples for two fields while three traps provided samples for the other field.

\section{Flower-visitor abundances}

A total of 1549 flower-visiting insects were counted (696 from B. rapa and 853 from B. napus fields). In both crops, $A$. mellifera was the most prevalent species found representing $43.1 \%$ of individuals in B. rapa and $37.2 \%$ in B. napus. The next most common was D. platura (B. rapa $10.1 \%$; B. napus 19.9\%), Bombus terrestris (Brassica rapa $12.2 \%$; B. napus $10.3 \%$ ), O. varia (B. rapa $3.7 \%$; $B$. napus $10.7 \%$ ) and various moths (B. rapa $10.3 \%$; B. napus $12.2 \%$ ). Of those species that were able to be identified most were Diptera (Table 1). 
Table 1 Mean count per trap of each taxa (95\% confidence limits) for each Brassica species. P was used to assess whether or not the ratio varied significantly from 1 .

\begin{tabular}{|c|c|c|c|c|}
\hline Order/Species & B. napus & B. rapa & $\begin{array}{l}\text { Ratio B. rapa } \\
\text { /B. napus }\end{array}$ & $\mathrm{P}$ \\
\hline \multicolumn{5}{|l|}{ Apideae } \\
\hline Apis mellifera (Linnaeus, 1758) & $14.4(9.1,22.9)$ & $12.5(7.8,20.1)$ & 1.15 & 0.634 \\
\hline Bombus terrestris (Linnaeus, 1758) & $4.0(2.5,6.4)$ & $3.5(2.2,5.7)$ & 1.13 & 0.687 \\
\hline \multicolumn{5}{|l|}{ Bombus hortorum (Linnaeus, 1761)/ } \\
\hline B. ruderatus (Fabricius, 1775) & $0.2(0.0,0.7)$ & $0.2(0.1,0.7)$ & 0.87 & 0.872 \\
\hline Lasioglossum sordidum (Smith, 1853) & $0.2(0.1,1.0)$ & $1.1(0.6,2.1)$ & 0.21 & 0.032 \\
\hline Leioproctus spp. & $0.1(0.0,0.4)$ & $0.0(0.0,0.3)$ & 2.18 & 0.511 \\
\hline \multicolumn{5}{|l|}{ Diptera } \\
\hline Delia platura (Meigen, 1826) & $7.7(3.0,19.9)$ & $2.9(0.7,12.7)$ & 2.65 & 0.214 \\
\hline Oxysarcodexia varia (Walker, 1836) & $4.1(1.7,10.0)$ & $1.1(0.2,5.6)$ & 3.82 & 0.106 \\
\hline Dilophus nigrostigma (Walker, 1848) & $1.0(0.4,2.4)$ & $1.0(0.4,2.3)$ & 1.00 & 0.994 \\
\hline Melangyna novaezelandiae (Macquart, 1855) & $0.6(0.2,1.5)$ & $0.8(0.4,1.7)$ & 0.71 & 0.516 \\
\hline Tachinidae sp. 1 & $0.6(0.2,2.5)$ & $0.5(0.1,2.3)$ & 1.17 & 0.856 \\
\hline Proscissio sp. & $0.4(0.1,3.3)$ & $0.7(0.1,3.2)$ & 0.61 & 0.672 \\
\hline Lucilia sericata (Meigen, 1826) & $0.4(0.2,0.8)$ & $0.5(0.3,0.8)$ & 0.89 & 0.800 \\
\hline Calliphora stygia (Fabricius, 1794) & $0.4(0.1,1.2)$ & $0.4(0.1,1.2)$ & 0.87 & 0.851 \\
\hline Eristalis tenax (Linnaeus, 1758) & $0.3(0.1,1.3)$ & $0.3(0.1,1.1)$ & 1.27 & 0.794 \\
\hline Odontomyia spp. & $0.4(0.1,1.0)$ & $0.2(0.0,0.7)$ & 2.18 & 0.334 \\
\hline Protohystricia alcis (Walker, 1849) & $0.4(0.1,1.2)$ & $0.0(0.0,1.0)$ & 9.82 & 0.071 \\
\hline Calliphora vicina (Robineau-Desvoidy, 1830) & $0.3(0.1,1.0)$ & $0.1(0.0,0.8)$ & 3.27 & 0.300 \\
\hline Pales usitata (Hutton, 1901) & $0.1(0.0,0.9)$ & $0.3(0.1,1.0)$ & 0.55 & 0.554 \\
\hline Tachinid spp. & $0.1(0.0,0.9)$ & $0.2(0.0,0.9)$ & 0.82 & 0.861 \\
\hline Anthomyia punctipennis (Weideman, 1830) & $0.2(0.1,0.7)$ & $0.0(0.0,0.5)$ & 5.45 & 0.135 \\
\hline Eumerus funeralis (Meigen, 1822) & $0.2(0.0,1.1)$ & $0.0(0.0,1.3)$ & 5.45 & 0.262 \\
\hline Melanostoma fasciatum (Macquart, 1850) & $0.1(0.0,0.7)$ & $0.1(0.0,0.6)$ & 1.64 & 0.665 \\
\hline Muscid spp. & $0.1(0.0,0.4)$ & $0.0(0.0, *)$ & - & - \\
\hline Helophilus hochstetteri Nowicki, 1875 & $0.0(0.0,0.3)$ & $0.0(0.0,0.3)$ & 1.09 & 0.951 \\
\hline Campbellia lancifer Malloch, 1930 & $0.0(0.0,0.3)$ & $0.0(0.0, *)$ & - & - \\
\hline Spilagona melas (Schiner, 1868) & $0.0(0.0,0.3)$ & $0.0\left(0.0,{ }^{*}\right)$ & - & - \\
\hline Therevidae spp. & $0.0(0.0,0.3)$ & $0.0(0.0, *)$ & - & - \\
\hline \multicolumn{5}{|l|}{ Coleoptera } \\
\hline Coccinella undecimpunctata (Linnaeus, 1758) & $0.3(0.1,1.4)$ & $0.4(0.1,1.4)$ & 0.85 & 0.850 \\
\hline Lepidoptera (moths) & $1.8(1.1,3.0)$ & $2.2(1.4,3.4)$ & 0.82 & 0.514 \\
\hline Overall/trap & $38.8(27.9,53.9)$ & $29.0(20.1,41.8)$ & 1.3 & 0.131 \\
\hline
\end{tabular}

- Cannot meaningfully calculate a ratio with $0 .{ }^{*}$ upper confidence limit for 0 is difficult to obtain so is omitted. 


\section{Diversity and richness of flower visitors between crop species}

Of the 29 taxa recorded (Table 1), 25 were collected in both crops. Counts were largely similar for each taxon although there were significantly higher catches of the bee L. sordidum in B. rapa (Table 1). There were no significant differences detected at the crop species level with respect to flower visitor diversity $(\mathrm{P}=0.834)$ or taxon richness (number of species; $\mathrm{P}=0.432$ ) (Fig. 1).

\section{Relationships between flower-visitor taxa and fields/crop species}

The correspondence analysis (Fig. 2) found the first two dimensions accounted for $74 \%$ (48\% and $26 \%$ ) of the variation in the data. Nine of the fields had similar scores on the first dimension being located to the right of the mean. In contrast, Mayfield is to the left (Fig. 2), indicating that the insect assemblage in this field varied noticeably from the other fields. This field contained relatively higher percentages out of the total of $O$. varia and D. platura (the two species furthest left of the mean) than the other sites (Fig. 2). There was greater differentiation between the other fields with respect to the second dimension, corresponding to a higher percentage in the

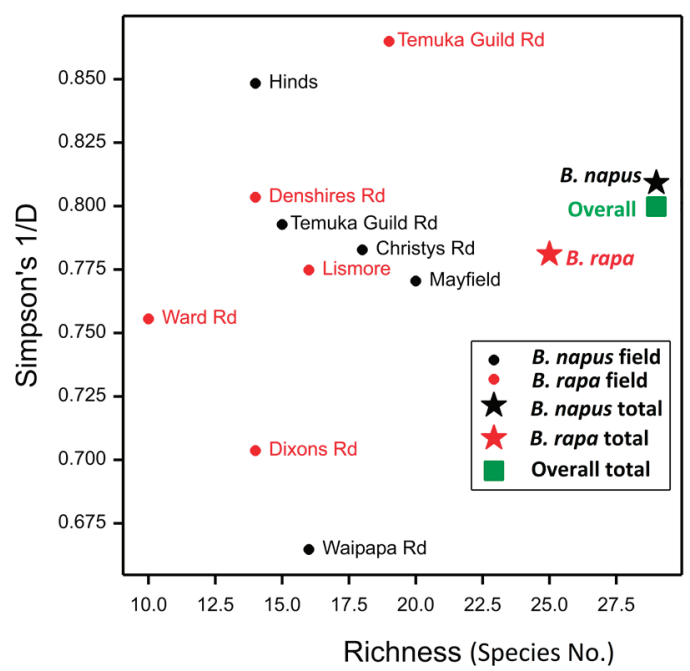

Figure 1 Taxon diversity (Simpson's 1/D) vs taxon richness (No. of taxa) across fields and crops species assemblage of $D$. platura at Temuka Guild $\mathrm{Rd}$ (furthest below the mean), while Dixons Rd (was furthest above the mean corresponding to a higher percentage out of the total of Proscissio sp. (Fig. 2). However, the strong overlap between the locations of the different crop species suggests no obvious differentiation in the insect assemblages relating to species (Fig. 2).

\section{Comparative size of floral structures}

The mean length of the measured floral structures was consistently greater for $B$. napus flowers compared to $B$. rapa, demonstrating a difference in floral structure size between these two cultivars (Table 2).

\section{DISCUSSION}

The findings obtained here support those from other studies (e.g. Pordel et al. 2007; Howlett et al. 2009a; Rader et al. 2012; Stanley \& Stout 2014) by demonstrating that Brassica spp. can attract a diverse assemblage of flower-visiting insects compromising both bees and non-bee insects. However, no evidence was found that the assemblages differed between B. napus and B. rapa across the region assessed. Both crops also had similar flower visitor taxon richness and

Table 2 Mean (Standard Deviation) length ( $\mathrm{mm}$ ) of six floral structures measured from flowers on primary inflorescences collected from five Brassica napus 'Winfred' and five B. rapa 'Hunter' fields (For both B. napus and B. rapa flowers $n=125)$.

\begin{tabular}{lrr}
\hline Floral Structure & $\begin{array}{c}\text { Brassica } \\
\text { napus }\end{array}$ & $\begin{array}{c}\text { Brassica } \\
\text { rapa }\end{array}$ \\
\hline Peduncle & $20.0(13.3)$ & $15.7(8.2)$ \\
Petal & $14.3(3.3)$ & $12.1(1.4)$ \\
Sepal & $7.4(3.2)$ & $6.9(3.3)$ \\
Stigma & $8.6(4.1)$ & $7.6(2.5)$ \\
Inner stamen & $10.8(4.8)$ & $9.1(4.8)$ \\
Outer stamen & $8.1(4.0)$ & $6.2(6.9)$ \\
\hline
\end{tabular}




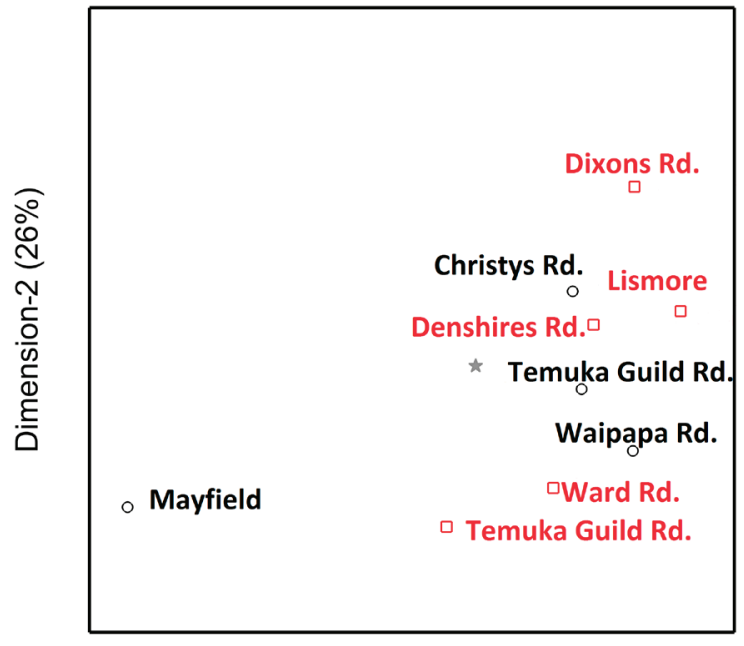

Dimension-1 (48\%)

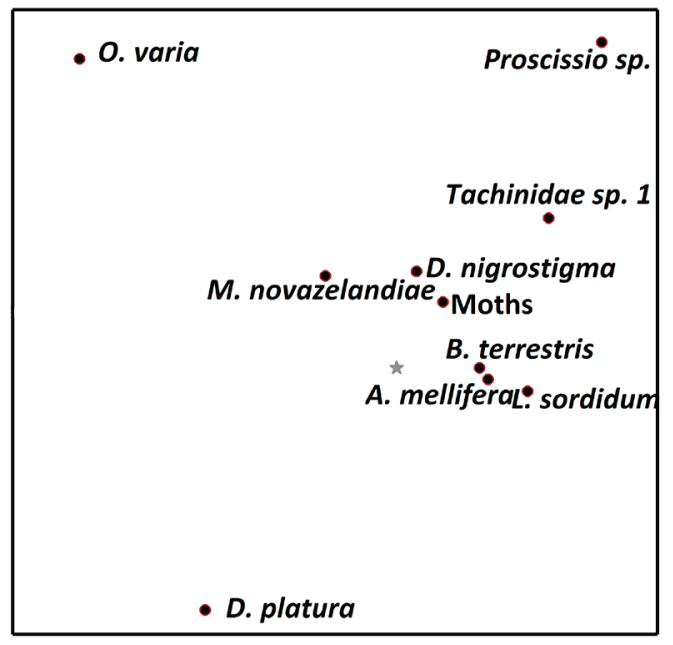

Dimension-1 (48\%)

Figure 2 Correspondence analysis asymmetric biplot, showing the principal score for each field (left) and standard scores (right) for each taxon. The principal scores are scaled by 3 to enable patterns to be seen. The star is at the mean. Black: B. napus. Red: B. rapa. The percentages indicate the amount of the total 'inertia' in the data that is associated with each of the two axes ('inertia' being analogous to variance; Greenacre 2007). Oxysarcodexia varia versus Proscissio spp. were particularly associated with differences between fields in the first dimension (x-axis) and Proscissio sp. versus D. platura were the species most associated with the second dimension ( $y$-axis).

diversity. Of the 29 taxa recorded in this study, all but four were found in both crops. Moreover, these four taxa were comparatively uncommon flower visitors in all the brassica fields. Both crops were dominated by similar flower visiting taxa with just one, the native bee L. sordidum, having significantly higher counts in $B$. rapa compared with $B$. napus fields. Reasons for the count difference remain unknown. Lasioglossum sordidum is the smallest bee collected in this study and the larger size of $B$. napus flower compared to $B$. rapa may be one of a number of factors that may have influenced its foraging choice.

It is well known that flower visitors commonly show visitation preferences between cultivars of the same crop species. In New Zealand, this has been observed for honey bees A. mellifera visiting radish (Raphanus raphanistrum subsp. sativus (L.) Dominand) (Evans et al. 2011), honey bees (A. mellifera), bumblebees (Bombus terrestris), and the native bees (L. sordidum and
Leioproctus sp.) visiting carrot (Howlett et al. 2015). However, when single varietal crops are grown in separate fields as in this study, local site factors can be the more important in influencing flower-visitor assemblage composition in at least some circumstances. The findings presented here (illustrated with correspondence analysis) imply that even over a relatively small spatial scale (all crops grown within a spatial radius of $40 \mathrm{~km}$ ) field location was more influential on flower-visitor assemblage composition than crop species. In New Zealand, a study by Rader et al. (2012) assessing a single cultivar of $B$. rapa found pollinator species abundances could be very variable between regions (Canterbury and Southland, South Island) and seasons, significantly influencing the relative pollinator effectiveness of different insect species. The regional and seasonal differences Rader et al. (2012) observed in pollinator abundances across fields were much more substantial 
than those found here between the two crop species sampled simultaneously within a single region. This is likely due to factors such as biogeographical restrictions of certain species (e.g. native and introduced bees (Donovan 2007)), habitat preferences (e.g. the fly O. varia was more abundant in open pasture compared to dense vegetation in contrast to certain species of calliphorid flies (Henning et al. 2005)) and seasonal variability in abundances (e.g. as observed for O. varia and different Calliphorid fly species (Howlett et al. 2016)).

The overlap among insect species visiting both $B$. rapa and $B$. napus in the current study highlights the potential role that many insect flower visitors could play in unwanted gene flow via pollen transfer between these two Brassica species in New Zealand. Some of the taxa identified here are known to move viable pollen from B. rapa crops into surrounding habitat with the flies Odontomyia spp., Melanostoma fasciatum, and Melangyna novaezelandiae, transporting it at least $400 \mathrm{~m}$ (Rader et al. 2011). Growers in New Zealand, currently isolate open-pollinated brassica seed crops at distances of $1 \mathrm{~km}$ and $2 \mathrm{~km}$ for hybrid seed crops (AsureQuality Limited, Seed Certification Bureau 2009). However, understanding the movement of the many pollinating insects would assist in achieving appropriate crop spacing to limit unwanted gene flow while maximising field-placement opportunities.

On the other hand, the inability to differentiate between the diverse flower visitor assemblages of both B. napus and B. rapa crops point to the potential to develop and apply pollinatormanagement strategies that support a similar set of diverse pollinating species. Brassica napus seed yield is known to increase in the presence of a combination of $A$. mellifera and other wild pollinating species compared with just $A$. mellifera alone (Garibaldi et al. 2013). Moreover, in New Zealand, many unmanaged insect species are capable pollinators of Brassica rapa (Rader et al. 2009; Howlett et al. 2011). Whether the same species are as equally efficient pollinators of $B$. napus in New Zealand needs to be assessed.

\section{ACKNOWLEDGEMENTS}

We thank PGG-Wrightson for their valuable assistance in identifying suitable fields and the growers for allowing access to their crops, and Linda Newstrom-Lloyd (Landcare Research) and John McCallum (PFR) for discussions leading to the collection of data. Preparation and publication of this work was supported through funding from Ministry of Business, Innovation and Employment C11X1309. Data was originally collected under the Foundation for Research Science and Technology programme CO2X0221.

\section{REFERENCES}

AsureQuality Seed Certification Bureau 2009. SCID, New Zealand Seed Crop Isolation Distance Mapping Scheme. 17 p. http:// maxa.maf.govt.nz/sff/about-projects/ search/05-122/nz-scid-mapping-scheme.pdf (accessed 7 April 2018).

Chifflet R, Klein EK, Lavigne C, Le Feon $\mathrm{V}$, Ricroch AE, Lecomte J, Vaissiere BE 2011. Spatial scale of insect-mediated pollen dispersal in oilseed rape in an open agricultural landscape. Journal of Applied Ecology 48: 689-696.

Donovan BJ 2007. Apoidea (Insecta: Hymenoptera). Fauna of New Zealand. Christchurch, Zealand Landcare Research Ltd. 295 p.

Evans LJ, Goodwin RM, Walker MK, Howlett BG 2011. Honey bee (Apis mellifera) distribution and behaviour on hybrid radish (Raphanus sativus L.) crops. New Zealand Plant Protection 64: 32-36.

Garibaldi LA, Steffan-Dewenter I, Winfree R, Aizen MA, Bommarco R, Cunningham SA, Kremen C, Carvalheiro LG, Harder LD, Afik $\mathrm{O}$ and others 2013. Wild pollinators enhance fruit set of crops regardless of honey-bee abundance. Science 339: 1608-1611.

Garratt MPD, Coston DJ, Truslove CL, Lappage MG, Polce C, Dean R, Biesmeijer JC, Potts SG 2014. The identity of crop pollinators helps target conservation for improved ecosystem services. Biological Conservation 169: 128135. 
Greenacre MJ 2007. Correspondence analysis in practice: Interdisciplinary Statistics. Chapman \& Hall/CRC, Boca Raton. 280 p.

Hayter KE, Cresswell JE 2006. The influence of pollinator abundance on the dynamics and efficiency of pollination in agricultural Brassica napus: implications for landscapescale gene dispersal. Journal of Applied Ecology 43: 1196-1202.

Henning J, Schnitzler FR, Pfeiffer DU, Davies $\mathrm{P}$ 2005. Influence of weather conditions on fly abundance and its implications for transmission of rabbit haemorrhagic disease virus in the North Island of New Zealand. Medical and Veterinary Entomology 19(3): 251-262.

Howlett BG, Donovan BJ, McCallum JA, Newstrom LE, Teulon DAJ 2005. Between and within field variability of New Zealand indigenous flower visitors to onions. New Zealand Plant Protection 58: 213-218.

Howlett BG, Walker MK, Newstrom-Lloyd LE, Donovan BJ, Teulon DAJ 2009a. Window traps and direct observations record similar arthropod flower visitor assemblages in two mass flowering crops. Journal of Applied Entomology 133: 553-564.

Howlett BG, Walker MK, McCallum JA, Teulon DAJ 2009b. Small flower-visiting arthropods in New Zealand pak choi fields. New Zealand Plant Protection 62: 86-91.

Howlett BG, Walker MK, Rader R, Butler RC, Newstrom-Lloyd LE, Teulon DAJ 2011. Can insect body pollen counts be used to estimate pollen deposition on pak choi stigmas? New Zealand Plant Protection 64: 25-31.

Howlett BG, Lankin-Vega GO, Pattemore DE 2015. Native and introduced bee abundances on carrot seed crops in New Zealand. New Zealand Plant Protection 68: 373-379.

Howlett BG, Davidson MM, Pattemore DE, Walker MK, Nelson WR 2016. Seasonality of calliphorid and sarcophagid flies across Canterbury arable farms requiring pollinators. New Zealand Plant Protection 69: 290-295.

Howlett BG, Evans LJ, Pattemore DE, Nelson
WR 2017a. Stigmatic pollen delivery by flies and bees: Methods comparing multiple species within a pollinator community. Basic and Applied Ecology 19: 19-25.

Howlett BG, Read SFJ, Jesson LK, Benoist A, Evans LE, Pattemore DE 2017b. Diurnal insect visitation patterns to 'Hayward' kiwifruit flowers in New Zealand. New Zealand Plant Protection 70: 52-57.

Magurran AE 2007. Species abundance distributions over time. Ecology Letters 10: 347-354.

McCullagh P, Nelder JA 1989. Generalized Linear Models. Chapman \& Hall, London. 511+xix p.

Mesa LA, Howlett BG, Grant JE, Didham RK 2013. Changes in the relative abundance and movement of insect pollinators during the flowering cycle of Brassica rapa crops: implications for gene flow. Journal of Insect Science 13: 13. https://doi. org/10.1673/031.013.1301

Payne R, Murray D, Baird D 2017. The Guide to the Genstat Command Language (Release 19). VSN International, Hemel Hempsted, Hertfordshire, UK.

Pordel MR, Hatami B, Mobli M, Ebadi R 2007. Identification of insect pollinators of three different cultivars of winter canola and their effect on seed yield in Isfahan. Journal of Science and Technology of Agriculture and Natural Resources 10: 413-426.

Rader R, Howlett B, Cunningham S, Westcott D, Newstrom-Lloyd L, Walker M, Teulon D, Edwards W 2009. Alternative pollinator taxa are equally efficient, but not as effective as the honeybee in a mass flowering crop. Journal of Applied Ecology 46: 1080-1087.

Rader R, Edwards W, Westcott D, Cunningham S, Howlett B 2011. Pollen transport differs among bees and flies in a human-modified landscape. Diversity and Distributions 17: 519-529.

Rader R, Howlett BG, Cunningham SA, Westcott DA, Edwards W 2012. Spatial and temporal variation in pollinator effectiveness: do unmanaged insects provide consistent pollination services to mass flowering crops? 
Journal of Applied Ecology 49: 126-134.

Rader R, Bartomeus I, Garibaldi LA, Garratt MPD, Howlett BG, Winfree R, Cunningham SA, Mayfield MM, Arthur AD, Andersson GKS and others 2016. Non-bee insects are important contributors to global crop pollination. Proceedings of the National Academy of Sciences of the United States of America 113(1): 146-151.

Read SFJ, Howlett BG, Jesson LK, Pattemore DE 2017. Insect visitors to Avocado flowers in the Bay of Plenty, New Zealand. New Zealand Plant Protection 70: 38-44.

Ronca S, Allainguillaume J, Ford CS, Warren J, Wilkinson MJ 2017. GM risk assessment: Pollen carriage from Brassica napus to B. rapa varies widely between pollinators. Basic and Applied Ecology 19: 36-44.

Stanley DA, Stout JC 2014. Pollinator sharing between mass-flowering oilseed rape and co-flowering wild plants: implications for wild plant pollination. Plant Ecology 215: 315-325.

Stavert JR, Linan-Cembrano G, Beggs JR, Howlett BG, Pattemore DE, Bartomeus I 2016. Hairiness: the missing link between pollinators and pollination. Peerj 4: 18. https://doi.org/10.7717/peerj.2779

Stewart AV 2002. A review of Brassica species, cross-pollination and implications for pure seed production in New Zealand. Agronomy New Zealand 32/33: 63-82.

Walker MK, Howlett BG, McCallum JA, Wallace AR, Teulon DAJ 2009. Small arthropods as pollinators in a New Zealand pak choi field trial. New Zealand Plant Protection 62: 9298. 